\title{
GUERRA SANTA E GLOBALIZAÇÃO
}

Sonia Reyes Herrera*

Conforme mostram as recentes análises sobre a religião, esta tem sido afetada pelo processo de globalização e de transnacionalização em escala mundial, tanto no lugar que ocupa na sociedade contemporânea quanto na função que ela desempenha (Beyer, 1997, Bastian, 1997, Pace, 1996, entre outros). Essa constatação empírica e teórica pode ser reveladora e fecunda para se pensar e deslocar o eixo de análise da guerra santa para fora do campo religioso ${ }^{1}$. Assim, pode-se perguntar até que ponto podemos refletir o conflito entre neopentecostais e afro-brasileiros inserido na sociedade e desde a perspectiva da globalização ${ }^{2}$, considerando também que esse campo não se desenvolve de forma autônoma e sim em interdependência com o sistema social mais amplo.

* Sonia Reyes Herrera é Mestre em Sociologia pela UFRGS e, atualmente, doutoranda em Sociologia pela UFRGS. Sua dissertação de mestrado intitula-se: "Representações e práticas sócio-religiosas dos camponeses pentecostais da Região da Araucária, no Chile". Desenvolve atualmente pesquisa sobre Nova Era.

1Conforme mostra o artigo "Neopentecostais e Afro-brasileiros: quem vencerá esta guerra?" os cientistas sociais tem dado diferentes interpretações ao conflito religioso entre esses dois setores. Sem reduzir os argumentos destas, poder-se-ia dizer que a primeira, enfatiza o conflito em termos da disputa por espaços no campo religioso popular brasileiro ("entre iguais"); a segunda, centra seu interesse na constituição do discurso (bélico) neopentecostal ("máquina narrativa") e; a terceira, o interpreta como um mecanismo posto em prática, especialmente pela IURD, para demarcar e acentuar sua diferença no campo evangélico ("outra forma de ser pentecostal").. Desde perspectivas e recortes diferentes essas análises abordam o conflito circunscrito ao campo religioso, com ênfase no estudo das crenças, discursos, práticas e estratégias dos diferentes agentes envolvidos, contribuindo assim ao conhecimento aprofundado da dinâmica interna do fenômeno.

2 Adoto aqui as concepções de Pace (1997) e Velho (1997). o primeiro considera a globalização como um instrumento metodológico para pensar o mundo; o segundo, enquanto um recurso cultural, um texto. Enfim, como um novo paradigma que deve ser considerado para o estudo das expressões e transformações do campo religioso contemporâneo.

Debates do NER, Porto Alegre, ano 1, n. 1, p. 53-61. Novembro de 1997. 
Adotando essa perspectiva é possível indagar, de que forma a Guerra Santa entre neopentecostais e afro-brasileiros é permeada pelo processo de globalização? Duas questões (a título de hipóteses) podem ser elucidativas para estabelecer essa relação: uma, a apropriação pelo neopentecostalismo de duas fórmulas que "circulam transnacionalmente", a Teologia da Guerra Espiritual e a Teologia da Prosperidade $^{3}$ (Corten, 1997), a outra, pensar o neopentecostalismo como a emergência (advento) de uma "nova singularidade religiosa", na sociedade brasileira, favorecida pelo processo de globalização. Pelas limitações de espaço que o texto apresenta, serão enunciados alguns elementos que poderiam ser indicadores dessa relação.

Conforme a classificação proposta por Freston (1996) a terceira onda denominada neopentecostal, caracteriza-se por "difundir e pregar a teologia da prosperidade (..), enfatizar a guerra espiritual contra o diabo (..) e não adotar os tradicionais $e$ estereotipados usos e costumes de santidade que até pouco fiiguravam como símbolos de conversão e pertencimento ao pentecostalismo" (Mariano, 1996:26). Sendo os dois primeiros conteúdos, que circulam globalmente, "importados" pelo neopentecostalismo, tratar-se-ia de observar como se colocam em relação com o local ${ }^{4}$. Assim, propõe-se considerar, por um lado, que a Teologia da Guerra Espiritual enquanto conteúdo ideológico, favorece, em nível micro, o alinhamento de marcos interpretativos do neopentecostalismo com a religiosidade brasileira, especialmente através da umbanda. Ao mesmo tempo e utilizada como estratégia para promover a conversão e adesão de novos adeptos. Por outro lado, a Teologia da Prosperidade, enquanto discurso doutrinário, que possibilita a inserção e acomodação do neopentecostalismo em nível

3 As formas de ingresso e difusão desses conteúdos parecem ser facilitadas principalmente pelos meios de comunicação, particularmente a difusão do teleevangelismo na década de 80, tradução de livros, além de outros mecanismos. Também pode-se considerar que a permanência do fundador da IURD nos Estados Unidos (1986-1989) teria facilitado essa adaptação. No dizer de Freston (1996: 134) a visita de Macedo "talvez houvesse o objetivo de assimilar seletivamente modelos americanos de ação religiosa". Nesse período se observa uma diversificação das atividades da IURD e uma penetração mais ousada de espaços sociais.

4 Segato (1997) sustenta que as crenças religiosas circulam globalmente mas se adaptam e inserem dentro de uma matriz nacional, localizando-se.

Debates do NER, Porto Alegre, ano 1, n. 1, p. 53-61. Novembro de 1997. 
macro $^{5}$.

O primeiro conteúdo que circula difundido por diversos continentes refere-se a "Teologia da Guerra Espiritual"6. O principal argumento desta é a expulsão dos demônios, o que conduz a libertação, sendo esta associada a cura e a prosperidade. Assim, essa seria uma das razões que permitiria explicar a demonização pentecostal das religiões afro-brasileiras, agindo como estratégia de evangelização e como mecanismo que favorece o alinhamento dos marcos interpretativos, proporcionando o sustento ideológico religioso aos ataques.

Considerando que o neopentecostalismo "importa" essa fórmula transnacionalizada, o ataque contra as religiões afrobrasileiras viria a significar o confronto entre o "global" e o "local", representados respectivamente pelos dois setores em conflito. Esse conteúdo globalizante, seguindo a análise proposta no artigo, se relacionaria com o local através de continuidade (frame amplification) e ruptura (frame transformation) de tal forma que coloca em relação elementos globais e locais, articulados em nível de práticas e crenças religiosas, reformulando seu conteúdo, dotando-o de novos significados. Desta forma, sobre o substrato religioso preexistente, a teologia da guerra espiritual ressignifica padrões culturais num discurso cristão que não se coloca em oposição à lógica da religiosidade local, senão que mostra precisamente a capacidade de adaptação que esse discurso possui ${ }^{7}$.

Pode-se pensar que o neopentecostalismo, operando com a

5 O conceito de alinhamento de marcos interpretativos em ambos os níveis encontrase trabalhado por Frigerio (1997), com base em bibliografia sobre movimentos sociais e religiosos. Resumidamente pode se assinalar que, o nível micro, indica a relação que estabelece o grupo com os indivíduos e o nível macro a relação que estabelece o grupo com a sociedade. Mais adiante será retomado o nível macro, o primeiro encontra-se definido no artigo "Neopentecostais ... ".

6 Cabe registrar que tanto a Teologia da Guerra Espiritual quanto a Teologia da Prosperidade tem sua origem nos Estados Unidos, o que poderia indicar a condição hegemônica desse país no processo de globalização em geral e em particular em matéria religiosa. Também é pertinente lembrar que o pentecostalismo surge nesse país no início deste século.

7 Cabe lembrar que Wagner e os outros autores desta teologia, identificam como seres com poder territorial as entidades de panteão religioso das culturas rurais, indígenas, animistas ou da mitologia grega (Wymarczyk, 1995).

Debates do NER, Porto Alegre, ano 1, n. 1, p. 53-61. Novembro de 1997. 
Teologia da Guerra Espiritual como novo marco interpretativo, se coloca em relação com o marco interpretativo anterior, retendo do local (continuidades) principalmente símbolos e práticas religiosas e, ao mesmo tempo, incorporando elementos globais, como: a ênfase no monoteísmo ao promover a "extinção" das diversas entidades religiosas locais. Nesse sentido, a observação de Pierucci (1997:260) referente a que : "uma parcela crescente do povo ao abraçar o protestantismo esta abandonando o politeísmo" torna-se pertinente. A ênfase no monoteísmo estaria também contribuindo para a secularização religiosa moderna e, com isso a incrementar o desencantamento do mundo. Conseqüentemente, poder-se-ia perguntar se a Teologia da Guerra Espiritual, enquanto conteúdo ideológico, estaria favorecendo no neopentecostalismo um tipo de religião mais ética e menos mágica e, ao mesmo tempo, a passagem de rituais mágicos para cultos religiosos?

Ainda que, no processo de sua constituição, o neopentecostalismo se aproxime e incorpore de forma ressignificada, alguns elementos da prática religiosa das religiões afro-brasileiras (umbandização da Igreja Universal?) em termos de crenças, distancia-se delas e do pentecostalismo tradicional operando, assim, uma grande transformação nesse imaginário em nível de conteúdos doutrinários. Isso se dá mediante a incorporação da outra fórmula tansnacionalizada: a Teologia da Prosperidade, que é completamente inovadora em matéria de comportamento religioso ${ }^{8}$. Esta corrente, também surgida nos Estados Unidos, fundamenta-se na crença de que o cristão está destinado a ser próspero materialmente, saudável, feliz e vitorioso em todos seus empreendimentos terrenos (Mariano, 1996) $)^{9}$.

Considerando que o neopentecostalismo opera com a Teologia da Guerra Espiritual em nível micro, trata-se de observar

8 Prandi (1996) sustenta que talvez a grande mudança que essa religião promove entre seus fiéis "esteja no convencimento de que todos tem direito a não-pobreza e de que todos deixaram realmente de ser pobres, o que inequivocamente quebra uma tradição de ressignação muito arraigada e muito imobilizadora" (1996: 271).

9 Sobre a origem e desenvolvimento da Teologia da Prosperidade, tanto nos Estados Unidos quanto no Brasil, Mariano (1996) e Freston (1996) constituem uma referência importante. Basta lembrar aqui, que a IURD constitui a porta de entrada desta teologia no Brasil.

Debates do NER, Porto Alegre, ano 1, n. 1, p. 53-61. Novembro de 1997. 
como a segunda fórmula transnacionalizada, isto é, a Teologia da Prosperidade, apropriada por este, pode estabelecer relações com a sociedade brasileira, posto que o conteúdo daquela viria a constituir o marco interpretativo do neopentecostalismo em nível macro ${ }^{10}$.

Esse discurso poderia ser colocar em correspondência ou estabelecer pontes com a sociedade (acomodação) através de dois aspectos principalmente:

a) A Teologia da Prosperidade, enquanto ideologia religiosa, pode ser posta em correspondência com os valores dominantes na sociedade de consumo e com a economia de mercado. O neopentecostalismo inserido no mercado de bens religiosos se coloca como oferta de resultados "superior nos benefícios que oferece", através de um discurso elaborado para atender as demandas imediatas de seus adeptos, adaptando suas mensagens as necessidades contemporâneas, compactuando com o mundo ${ }^{11}$. Ao mesmo tempo, ao dar menor ênfase a conversão, favorece um tipo de religião privatizada, mais ou menos liberada de controles institucionais.

b) Onde mais se observa essa correspondência é na possibilidade de ascensão social que oferece, chegando essa a assumir um conteúdo sacralizado, na medida que se alcança através de mediações religiosas. Se analisada a oferta de mobilidade social, promovida pelo neopentecostalismo, no contexto da sociedade brasileira atual, onde o modelo econômico neoliberal gera uma crescente exclusão social, pode-se observar que esta opção religiosa oferece uma fórmula de acesso à modernidade e a um estilo de vida adaptado aos valores dominantes. Dessa forma, dirige sua mensagem a um setor da população que não esta completamente marginalizado ou excluído

10 Conforme as análises de Frigerio (1997), trata-se de analisar neste aspecto como o grupo ou movimento se insere ou adapta na sociedade. Neste processo, os autores por ele citados (Herper e Le Beaus, 1993, e Snow, 1979), observam que a adaptação social pode ser localizada em um continuum entre um extremo positivo (acomodação) isso significa que o movimento pode subsistir sem gerar muita controvérsia e um extremo negativo (problematização) que implica hostilidade e conflito em relação ao mesmo.

11 Pace (1997) identifica dois processos que caracterizam a dinâmica do campo religioso mundial, a partir dos anos 80, sendo um deles, o esforço de adaptação realizado por diferentes formações sócio-religiosas, grandes ou pequenas, para não ficar fora do mundo moderno e de suas linguagens.

Debates do NER, Porto Alegre, ano 1, n. 1, p. 53-61. Novembro de 1997. 
do sistema econômico e que potencialmente apresenta possibilidades reais de ascensão social ou, no mínimo, a expectativa de superação.

Entretanto, esse processo de acomodação do neopentecostalismo à sociedade brasileira na sua emergência e desenvolvimento ${ }^{12}$, também pode ser localizado no extremo da problematização, isto é, nas relações de hostilidade e conflito. Nesse sentido a guerra religiosa (afro-brasileiros, protestantes tradicionais e católicos) constitui uma expressão visível desse processo. Conforme Prandi "é essa agressividade dos pastores que explica em grande medida o sucesso dessa religião; a expansão desse mercado depende muito do estilo da oferta, de sua propaganda e de sua linguagem" (Prandi, 1996: 258). A heterofobia, conforme definida no artigo "Neopentecostais ..." , também age como uma estratégia de acomodação agressiva na sociedade por parte do neopentecostalismo, entre outras. Cabe destacar que nesse processo outros setores da sociedade também entram em conflito e hostilidade com o grupo ou movimento emergente.

A segunda questão proposta, a título de hipótese, neste trabalho, diz respeito a até onde a Guerra Santa pode ser indicativa de um processo de emergência e desenvolvimento de uma "nova singularidade religiosa" (neopentecostalismo) na sociedade brasileira, favorecido pelo processo de globalização.

O neopentecostalismo, incorporando em sua constituição essas duas fórmulas transnacionalizadas e a tradição religiosa brasileira, principalmente, através da umbanda, introduz a tradição do catolicismo popular as religiões afro-brasileiras. Ao mesmo tempo, adota categorias do pentecostalismo tradicional ressignificando-as, "sendo idênticas e diferentes; salvação é ao mesmo tempo solução, conversão é libertação e louvor é prosperidade" (Corten, 1997: 10). Tudo isso lhe permite consolidarse como uma nova expressão religiosa, criando um estilo particular ao combinar elementos globais e locais, colocando-se em um lugar de destaque na sociedade brasileira.

12Seria importante analisar comparativamente a emergência e expansão da umbanda e do neopentecostalismo procurando identificar semelhanças e diferenças que apresentam ambos os processos, considerando os contextos diferenciados e o fato de que se trata de uma religião não-cristã e uma religião cristã.

Debates do NER, Porto Alegre, ano 1, n. 1, p. 53-61. Novembro de 1997. 
Assim, essa "nova singularidade religiosa" ("made in Brazil"), integra elementos de diversos universos simbólicos, retendo a diversidade do local, dotando-os de novos significados mediante a apropriação de um discurso religioso que circula globalmente. Desta forma, a Teologia da Guerra Espiritual (expulsão de demônioslibertação) se constitui numa estratégia eficaz para reforçar a relação do grupo com o indivíduo e a Teologia da Prosperidade, (realização e bem-estar material no mundo) atualiza a mensagem religiosa em determinado grau de correspondência com a ideologia dominante na sociedade onde se insere.

\section{Duas reflexões para concuir.}

Cabe perguntar se a Guerra Santa, inserida na sociedade brasileira e observada desde a perspectiva da globalização, não nos coloca na presença de um fenômeno de "globalização religiosa", enquanto relação de elementos globais e locais, expresso na emergência e desenvolvimento do neopentecostalismo? Se assim for, a Guerra Santa representaria uma tensão nas relações de interpenetração entre local-global, processo que não se dá sem conflitos nem de forma harmônica e que acarreta implicações para ambos os pólos.

O processo de globalização traz conseqüências, invariavelmente, tanto para o global quanto para o local. Sem dúvida resta observar como as religiões afro-brasileiras reagem a/e nesse processo. De fato, constata-se, por um lado, que elas transnacionalizam-se em ritmo crescente, mostrando que o Brasil não somente importa como exporta diversas sociabilidades religiosas e, por outro lado, conforme indica o artigo "Neopentecostais ..." a Guerra Santa poderia, até certo ponto, estar forçando essas religiões a adoção de um modelo institucional. Porém, pode-se perguntar se essa institucionalização não estaria mais condicionada pelas transformações que experimenta o sistema religioso inserido no processo de globalização como um todo?

Debates do NER, Porto Alegre, ano 1, n. 1, p. 53-61. Novembro de 1997. 


\section{Referências Bibliográficas}

BASTIAN, Jean Pierre. La deregulation religieuse de l'Amerique Latine. In: Problemes d'Amerique Latine, n.24, janv.- mars, 1997, pp.3-15.

BEYER, Peter. A privatização e a influência pública da religião na sociedade global. In: FEATHERSTONE, Mike. Cultura Global: Nacionalismo, globalização e modernidade. Petrópolis, Vozes, 1994, p. 395-419

. The city and beyond as dialogue: negotiating religious authenticity in global society. Paper apresentado no congresso da International Society for the Sociology of Religion, Toulouse, 7-11 de julho de 1997.

CORTEN, André. Discours transnationalise et besoins religieux. Paper paresentado no Congresso da International Society for the Sociology of Religion. Toulouse, 7-11 de julho, 1997 (versão provisória).

FRIGERIO, Alejandro. Estabelecendo pontes: articulação de significados e acomodação social em movimentos religiosos no Cone-SuI. In: ORO, Ari Pedro e STEIL, Carlos Alberto (Orgs.). Globalização e Religião. Petrópolis, Vozes, 1997, pp. 153-177.

FRESTON, Paul. Breve história do pentecostalismo brasileiro. In: Nem anjos nem demônios. Petrópolis, Vozes, 1994, pp. 67-159.

MARIANO, Ricardo. Os neopentecostais e a teologia da prosperidade. In: Novos Estudos CEBRAP, n.44, março, 1996, pp. 24-44.

PACE, Enzo. Religião e Globalização. In: ORO, Ari Pedro e STEIL, Carlos Alberto (Orgs.). Globalização e Religião. Petrópolis, Vozes, 1997, p. 25-42.

PIERUCCI, Flávio, PRANDI, Reginaldo. A realidade social das religiões no Brasil. São Paulo, Hucitec, 1996.

PRANDI, Reginaldo. As religiães negras do Brasil. Para uma sociologia dos cultos afro-brasileiros. In: Revista USP-Dossiê Povo Negro 300 anos, n.28, dez./jan./fev. 1995-96, pp. 64-83.

SANCHIS, Pierre. O rapto pentecostal à cultura cató1ica brasileira. In: Nem

Debates do NER, Porto Alegre, ano 1, n. 1, p. 53-61. Novembro de 1997. 
anjos nem demônios. Petr6polis, Vozes, 1994, pp.34-66.

SEGATO, Laura. Formações de diversidade: nações e opções religiosas no contexto da globalização. In: ORO, Ari Pedro e STEIL, Carlos Alberto (Orgs.). Globalização e Religião. Petrópolis, Vozes, 1997, pp. 219-248.

VELHO, Otávio. Globalização: Antropologia e Religião. In: ORO, Ari Pedro e STEIL, Carlos Alberto (Orgs.). Globalização e Religião. Petrópolis, Vozes, 1997, pp. 43-61. 